\title{
A História de Nair: a Força da Identidade Institucional para a Permanência na Docência em Matemática
}

\author{
The Story of Nair: the Strength of the Institutional Identity for Permanence \\ in Mathematics Teaching
}

\author{
Mônica Lana da Paz \\ Cristina Frade ${ }^{* *}$
}

\begin{abstract}
Resumo
Este artigo retrata a compreensão dos significados associados às escolhas de Nair pela sua permanência na docência em Matemática. Sob a luz de uma perspectiva social da construção da identidade profissional, realizouse uma pesquisa empírica, cuja produção de dados se deu na forma de entrevista semiestruturada. Tomou-se como principal orientação teórica as contribuições de James Paul Gee sobre identidade. Os resultados de pesquisa mostraram: (i) a força que a identidade institucional de Nair exercia em sua permanência na docência; (ii) que esse tipo de identidade era sustentada por vocação pela prática docente e pelo prazer que a docência lhe proporcionava. Esses resultados sugerem, ainda, que a identidade docente é sempre reconstruída em um contexto histórico e social que transforma, constantemente, as ações do professor em sua prática profissional.
\end{abstract}

Palavras-chave: Matemática. Identidade Institucional. Docência. Professor.

\begin{abstract}
This article portrays the understanding of the meanings associated with Nair choices for remaining in Mathematics teaching. In the light of a social perspective for the professional identity construction, we held an empirical research, which data production was in the form of semi-structured interview. We used as main theoretical orientation the James Paul Gee contributions about identity. The research results showed: (i) the strength that Nair's "institutional identity" exercised in her time in teaching; (ii) that such identity was supported by the vocation of teaching practice and the pleasure that teaching gave her. These results also suggest that the teaching identity is always rebuilt in a historical and social context that constantly changes the teacher's action in their professional practice.
\end{abstract}

Keywords: Mathematics. Institutional Identity. Teacher Profession. Teacher.

\section{Introdução}

\footnotetext{
* Doutora em Educação pela Universidade Federal de Minas Gerais (UFMG). Professora do Instituto Federal de Educação, Ciência e Tecnologia de Minas Gerais (IFMG), Formiga, Minas Gerais, Brasil. Endereço para correspondência: Instituto Federal Minas Gerais, Campus Formiga. Padre Alberico, 440, São Luiz, 35570-000, Formiga, Minas Gerais, Brasil. E-mail: monica.lana@ifmg.edu.br

** Doutora em Educação pela Universidade Federal de Minas Gerais (UFMG). Professora e pesquisadora do Programa de Pós-graduação: Conhecimento e Inclusão Social da Faculdade de Educação, Universidade Federal de Minas Gerais (UFMG), Belo Horizonte, Minas Gerais, Brasil. Endereço para correspondência: Av. Antônio Carlos, 6627, Pampulha, 31270-901, Belo Horizonte, Minas Gerais, Brasil. E-mail: cristinafrade@ufmg.br 
Já se foi o tempo em que a docência era uma atividade de destaque e ocupava certo status na sociedade. Diferentemente disso, hoje, o professor muitas vezes é caracterizado como um desfavorecido socialmente, sobretudo aqueles que se dedicam ao trabalho nos ensinos Fundamental e Médio das escolas públicas brasileiras.

Dados da Confederação Nacional dos Trabalhadores em Educação (CNTE) de 2007 previram que o Brasil apresentaria uma situação alarmante para a próxima década, qual seja não ter professores para atuar no Ensino Médio da Rede pública (BRASIL, 2007).

Os dados da CNTE mostram que a categoria é atingida por altos índices de afastamento por problemas de saúde e de faltas ao trabalho por problemas de exaustão. Esse estudo revela, ainda, que, entre as causas apontadas para o pouco interesse dos jovens pela profissão, estão os baixos salários, a violência nas escolas e a superlotação das salas de aula (BRASIL, 2007, p. 13).

Resultados da Pesquisa Internacional sobre Ensino e Aprendizagem (Teaching and Learning International Survey - TALIS) da Organização para a Cooperação e Desenvolvimento Econômico (OCDE), realizada em 2012/2013 e divulgada em 2014, indicaram que os professores brasileiros são aqueles que mais trabalham entre os 100 mil professores pesquisados em 34 países ${ }^{1}$. No Brasil, os professores dedicam-se a 25 horas de ensino por semana, carga horária constatada superior em 6 horas em relação à média internacional (OCDE, 2014). Além disso, a pesquisa constatou que os estudantes brasileiros são os mais indisciplinados em relação aos países pesquisados. No contexto educacional brasileiro, os professores gastam menos de $70 \%$ do tempo destinado às aulas com ensino. Tal constatação retrata um grave problema que os professores brasileiros vivenciam no trabalho ao serem, de certa forma, obrigados a usarem um tempo que deveria ser destinado ao processo de ensino e aprendizagem no controle de disciplina em sala de aula (OCDE, 2014).

De acordo com relatório publicado pela OCDE (2006), o salário dos professores na maior parte dos países membros da Organização se reduziu nos últimos vinte anos quando se compara com outras profissões que requerem o mesmo nível de formação. Ressaltamos o fato de que o valor da hora de trabalho pago ao professor é muito inferior a de outros profissionais que possuem a mesma escolaridade e, até mesmo, com nível escolar mais baixo, como mostra a literatura.

O professor ganha mal, em muitos casos, apenas com o que ganha não é possível fechar as contas bancárias do mês, compara seu salário ao de seus colegas engenheiros, analistas de sistemas, todos com curso superior como ele, e descobre que é quem ganha menos. Compara seu salário com o de outros funcionários públicos do Estado e constata que está entre os que ganham pior para o seu nível de formação e responsabilidade (ODELIUS; RAMOS, 1999, p. 340).

\footnotetext{
${ }^{1}$ Para maiores informações pesquisar em http://talis.inep.gov.br/paises-participantes.
} 
Fica, então, um constante conflito entre aquilo que o professor acredita ser e o que a realidade lhe mostra, interferindo diretamente na maneira como se dá a construção da sua identidade profissional. É fato que a docência é desvalorizada. O discurso presente na sociedade desde quando uma criança se inicia na vida escolarizada é que estude e encontre um emprego que lhe permita ganhar dinheiro. Consequentemente, a docência não está incluída entre as profissões mais procuradas. "Por essa razão não está entre as profissões almejadas, apesar de continuar sendo um trabalho interessante, importante, desejado" (ODELIUS; RAMOS, 1999, p.341). Segundo pesquisa TALIS divulgada em 2014, aproximadamente 90\% dos professores brasileiros reconhecem a docência como uma prática desvalorizada socialmente. Contudo, $87 \%$ desses professores declaram estar realizados no trabalho (OCDE, 2014).

É fato, também, que muitos professores duplicam e, até mesmo, chegam a triplicar sua jornada de trabalho, para aumentar seu rendimento salarial. Como resultado disso, o desempenho do professor é afetado (BRASIL, 2003). O professor acaba por assumir um excesso de atividades - o que provoca um desgaste tanto físico, quanto mental. Nessas condições, o professor está vulnerável a desenvolver problemas de saúde desencadeados por um quadro de stress. É necessário que o trabalhador tenha expectativas promissoras em relação a sua vida profissional - o que pode representar reconhecimento do trabalho desempenhado.

Outro aspecto a ser considerado e que está associado à má remuneração são as condições de trabalho. Muitas vezes, as escolas não têm infraestrutura, sem contar que, em muitos casos, não é possível ter o apoio da família no processo de aprendizagem dos alunos. Diante disso, é necessário que o professor reelabore práticas diferenciadas constantemente no intuito de atender às demandas dos alunos. Tudo isso contribui para um quadro de sofrimento psíquico dos professores (ODELIUS; RAMOS, 1999). Mesmo assim, há, ainda, aqueles que optam pelo magistério.

Neste artigo apresentamos os resultados de uma pesquisa ${ }^{2}$ sobre a permanência na docência: o caso de $\mathrm{Nair}^{3}$ - professora de Matemática, sob uma perspectiva social da construção de sua identidade. Tomam-se, como principal orientação teórica, as contribuições de Gee (2000) sobre identidade, segundo a qual "as pessoas possuem múltiplas identidades conectadas não aos seus 'estados internos', mas aos seus desempenhos na sociedade" (GEE, 2000, p.99). Com base nisso, esse pesquisador propõe quatro perspectivas para se

\footnotetext{
${ }^{2}$ Ver Paz (2013) para acesso à pesquisa completa. O presente artigo traz um recorte dessa pesquisa. ${ }^{3}$ Utilizamos pseudônimos para os professores participantes da pesquisa no intuito de preservar o anonimato.
} 
compreender a construção identitária: Identidade Natural, identificada como estado (Natureza - biológica); Identidade Institucional, identificada como posição institucional assumida por vocação ou imposição; Identidade Discursiva, identificada como características individuais resultantes de interações com outros (pessoas, contextos) e Identidade de Afinidade, identificada a partir das experiências vivenciadas em grupos de afinidade.

Inspiradas nas contribuições de Gee (2000), perguntamos: quais os motivos que mantêm Nair na docência? O que podemos dizer sobre a manifestação das múltiplas identidades, tal como o autor propõe, na decisão de Nair pela permanência na prática docente?

Para responder a essas questões realizamos uma pesquisa qualitativa, na qual se empregou uma entrevista semiestruturada para a produção dos dados.

Para a construção de uma trajetória de análise da permanência de Nair na docência, consideramos estudar o fenômeno permanência via constituição da identidade de professores de Matemática. Isso porque tomamos como pressuposto que a escolha profissional de um sujeito está intrinsecamente ligada à construção de sua identidade. Apoiadas, tanto pela prática, quanto pela literatura, consideramos que os elementos que orientam as opções profissionais dos indivíduos estão associados às imagens que esses indivíduos incorporam a suas identidades. Essas imagens referem-se a si mesmos, às suas funções, às suas práticas e às relações interpessoais de ordem histórica (socioeconômicas e político-culturais), formando uma base para a busca de sentidos para a profissão. Tal busca de sentido está intimamente relacionada à construção de uma identidade que ocorre, não somente devido a escolhas e julgamentos individuais, mas, notadamente, em função de outros sociais (FRADE; MEIRA, 2010). Apresentamos, inicialmente, a discussão teórica que fundamentou a investigação. Em seguida, descrevemos a trajetória metodológica da pesquisa. A partir de um mapeamento dos tipos de identidade propostos por Gee (2000), analisamos e interpretamos a história de Nair em termos da permanência na docência em Matemática. Por fim, apresentamos as considerações resultantes da investigação.

\section{Identidade - abordagem conceitual para análise da permanência de Nair na prática docente}

O tema identidade tem sido objeto de investigação de várias áreas do conhecimento, tais como a antropologia, a sociologia, a psicologia e a psicologia social. Disto resulta que a conceituação do termo identidade e os sentidos atribuídos ao seu desenvolvimento são marcados por uma multiplicidade de perspectivas, o que, por sua vez, é um indicador da 
complexidade de estudo sobre o tema. No campo da Educação Matemática encontramos estudos sobre a construção da identidade sob diferentes focos e perspectivas teóricas. Algumas pesquisas de Sfard e Prusak (2005), Lerman (2006), Boaler (2002), Boaler; Willian e Zevenbergen (2000) incidem o foco no ensino e aprendizagem da matemática escolar. Outras, por exemplo Ponte (1995), Brown (2003), Hodgen (2004), Fiorentini (2008), Frade e Meira (2010), Gómez-Chacón (2010), Goldin; Roesken e Toener (2010), Krzywacki e Hannula (2010), Brown e Mcnamara (2011), Lerman (2012), e Gama e Fiorentini (2008) dedicam-se ao contexto do desenvolvimento profissional de professores de Matemática. Os estudos de Hodgen (2004), Ponte (1995), Walshaw (2004), Fiorentini (2008), Brown e Mcnamara (2011), Ponte e Oliveira (2002), dentre outros, explicitam uma preocupação da comunidade de Educação Matemática no desenvolvimento de pesquisas que abordem a construção da identidade do professor de Matemática frente ao processo de formação para a docência.

A opção conceitual de identidade, adotada nesta pesquisa, aproxima-se, notadamente, de uma perspectiva sociocultural (GROOTENBOER; SMITH; LOWRIE, 2006), à medida que partimos do pressuposto de que a construção da identidade é um processo que emerge de práticas sociais e culturais. Dito isso, tomamos como principal orientação teórica a perspectiva de Gee (2000) por abarcar, no nosso entender, muitas das abordagens sobre identidade em termos, pelo menos, de dois pressupostos centrais: (i) a ideia de que as pessoas são como são, em função de seus posicionamentos nos diversos contextos sociais de que participam (múltiplas identidades); (ii) a noção de identidade como sendo dinâmica, sempre sujeita a mudanças.

Gee (2000) chama a atenção para o fato de que a globalização e as transformações desencadeadas no mundo por esse fenômeno fizeram com que pesquisadores de várias áreas encontrassem no estudo da identidade uma forma de entender o universo escolar e a própria sociedade. Ele destaca que sua perspectiva conceitual acerca da identidade distancia do foco centrado em raça, gênero e classe, e passa a considerar a interação dos sujeitos, nos variados contextos dos quais participam, como determinante da construção identitária desses sujeitos. O interesse de Gee (2000) não é o de fazer um estudo sobre os vários significados atribuídos ao termo identidade, mas delinear uma noção de identidade que possa ser utilizada como uma ferramenta analítica para a pesquisa em Educação. O conceito de identidade introduzido por Gee (2000) está vinculado à ideia de um indivíduo ser reconhecido como certo tipo de pessoa em determinado contexto. Para o pesquisador, identidades são produtos das experiências que 
os indivíduos vivenciam em cada contexto social de que participam, rejeitando-se a associação da construção da identidade somente à dimensão pessoal.

Gee (2000) parte da ideia de como as identidades estão associadas para o funcionamento de forças históricas, institucionais e socioculturais. Ele desenvolve o conceito de identidade com base em quatro perspectivas que permitem compreender o que é ser reconhecido como certo tipo de pessoa em determinados contextos. Essas quatro perspectivas são: Identidade Natural (Identidade - N) identificada como estado (Natureza - biológica); Identidade Institucional (Identidade - I) identificada como posição institucional; Identidade Discursiva (Identidade - D) identificada como características individuais, mas construídas socialmente, e Identidade de Afinidade (Identidade - A) identificada a partir das experiências vivenciadas em grupos de afinidade.

O pesquisador chama a atenção para o fato de que essas quatro perspectivas não são separadas uma das outras. Entretanto, ele argumenta que é possível questionar, considerando um determinado contexto, se existe a predominância de uma das perspectivas e a justificativa para tal predominância. Cada uma das perspectivas que ele apresenta para tratar a identidade são maneiras de visualizar distintos aspectos de como as identidades são construídas e sustentadas.

A primeira perspectiva refere-se à Identidade Natural. Para Gee (2000), isto quer dizer que o indivíduo assume, em grande parte, seu modo de ser em virtude de sua natureza biológica. Entretanto, é importante destacar que Gee (2000) não limita a identidade a um processo biológico. Isto também não quer dizer que os aspectos biológicos sejam desconsiderados. O que o pesquisador enfatiza é o fato de que os aspectos biológicos não são fatores únicos que definem o tipo de pessoa que um indivíduo representa na sociedade. Ao conceituar a Identidade - $N$, Gee (2000) toma como exemplo parte do que representa a sua vida. Ele é um gêmeo idêntico, algo que representa parte de sua identidade e, portanto, uma forma de olhar para si mesmo. O fato de ser gêmeo idêntico representa um estado ou, dito de outra forma, uma característica genética. A fonte desse estado (gêmeo idêntico) é a natureza. Gee (2000) expõe que as Identidades - N, para serem sustentadas, precisam de reconhecimento, seja por si mesmo ou por outros: "Identidades - $\mathrm{N}$ sempre reforçam suas forças como identidades através do trabalho de instituições, de discurso e diálogo, ou grupos de afinidade, isto é, as próprias forças que constituem nossas outras perspectivas sobre identidade" (GEE, 2000, p. 102).

Gee (2000) esclarece que a Identidade - $N$ como um gêmeo idêntico pode ser sustentada por uma instituição (pesquisadores nos estudos de matrizes genéticas) ou, de outra 
forma, por meio das pessoas, sob vários aspectos, ao considerar que ele é um gêmeo idêntico, ou mesmo na participação de grupos de afinidade que incluem a participação exclusiva de gêmeos. Conforme demonstra Gee (2000), as Identidades $-N$ recaem sobre outros tipos de identidade.

A segunda perspectiva denominada por Gee (2000), Identidade Institucional, leva em conta que o papel que o indivíduo ocupa na sociedade é preponderante na forma como esse indivíduo é reconhecido socialmente. Associados à forma como o indivíduo é reconhecido na sociedade estão os princípios que permeiam o papel por ele ocupado - a posição assumida socialmente. Por trás dessa posição estão as regras, estatutos, e tudo aquilo que institucionalmente rege e determina sua maneira de se posicionar diante do papel social a que está vinculado. Para exemplificar a Identidade - I, Gee (2000) volta a mencionar um aspecto de sua vida. Ele é um professor universitário - o que representa parte de sua identidade. Ser professor é uma posição que ele ocupa e essa posição não é determinada pela sua Identidade $N$, mas por meio de uma instituição, ou seja, a universidade onde ele atua profissionalmente. O que sustenta a Identidade - I é um conjunto de leis, regras e princípios que regulamentam a profissão. Ainda, para Gee (2000), a Identidade - I pode ser reconhecida como uma imposição ao indivíduo ou uma vocação (chamado). Ele admite sua Identidade - I (professor universitário) como uma vocação.

Já a terceira perspectiva de identidade apresentada por Gee (2000), Identidade Discursiva é caracterizada em termos das relações estabelecidas com outras pessoas. Ainda, a visão que o outro tem sobre mim é determinante para configurar a minha identidade. É a partir do discurso estabelecido com outras pessoas que se dá esse reconhecimento. Para descrever a Identidade Discursiva, Gee (2000) relata outro exemplo interessante. Ele tem uma amiga que é considerada carismática - o que constitui parte de sua identidade. Ser carismática não é uma característica da sua Identidade - $N$ e muito menos uma posição sustentada institucionalmente (por meio de leis, regras e princípios). Segundo Gee (2000), o que sustenta a Identidade - D são as pessoas racionais. As pessoas se relacionam, interagem e se representam a partir do discurso - o que Gee (2000) justifica para utilizar o termo racional. Desse modo, ser carismático é uma característica individual, mas não é um atributo que se consegue sozinho, pois há necessidade do discurso de outras pessoas para sustentar tal característica. Gee (2000) destaca que a sustentação da identidade ocorre a partir do discurso. Por sua vez, os discursos são considerados resultados de um processo social. São justamente os discursos que atuam nos distintos papéis que os indivíduos assumem na sociedade, possibilitando a escolha de pertencimento a determinados grupos sociais. 
As pessoas não necessitam sustentar identidades por meio de autoridades institucionais. Tal sustentação pode ocorrer a partir do discurso e diálogo (GEE, 2000). Já as instituições carecem de práticas discursivas na sustentação de Identidades - I. Uma universidade depende de interações sociais para legitimar a identidade do professor. Não basta que a universidade apresente o sujeito como professor, pois são necessários discursos que permitam sustentar a sua Identidade - I.

Por fim, Gee (2000) refere-se à Identidade de Afinidade - A. Nesse caso, a identidade é articulada àquilo que causa prazer e satisfação: o indivíduo pode assumir determinado papel na sociedade a partir da afinidade construída com determinados grupos por compartilharem interesses comuns. Para Identidade de Afinidade - A, Gee (2000) menciona como exemplo os fãs (trekkies) do filme Jornada nas Estrelas (Star Trek). O grupo que constitui os trekkies estão reunidos em torno de interesses comuns constituindo, portanto, um grupo de afinidade. Não é a natureza, uma instituição ou discursos que sustentam a identidade desse grupo, mas a participação em práticas que são específicas aos trekkies, embora um discurso próprio possa ser desenvolvido nessas práticas.

Em sua definição: "O que as pessoas do grupo compartilham e devem compartilhar para construir um grupo de afinidade é a fidelidade, acesso e participação em práticas específicas proporcionadas a cada um dos membros do grupo como experiências indispensáveis" (GEE, 2000, p. 105).

No caso do professor de Matemática, uma forma de exemplificar a construção da identidade de afinidade é por meio de sua participação, por exemplo, na Sociedade Brasileira de Educação Matemática, cujos membros compõem um grupo de afinidade por compartilharem interesses comuns.

A teoria de Gee (2000) propõe que as identidades múltiplas de um sujeito possam ser compreendidas em termos das perspectivas aludidas acima sobre identidade, podendo ser, todas elas, interligadas. Um sujeito pode se reconhecer de várias formas a partir dessas distintas perspectivas, bem como reconhecer o outro de várias maneiras e também ser reconhecido pelo outro por diversas facetas. Em um determinado momento e lugar, o sujeito pode agir, utilizar a linguagem escrita ou oral, se apresentar, se posicionar, se vestir, ter suas crenças e, tudo isso pode acontecer de distintas maneiras, além de dispor de uma série de outras coisas de diversas outras formas. O conjunto de tudo isso, inserido em diferentes contextos, faz com que o indivíduo seja reconhecido como um determinado tipo de pessoa (GEE, 2000). 
Até aqui descrevemos a perspectiva de identidade introduzida por Gee (2000). Tal perspectiva o levou a realizar uma pesquisa empírica nos moldes da observação participante em um contexto de sala de aula (turma de alfabetização / second-grade class) com grande diversidade cultural. A partir de interações estabelecidas entre os alunos e professor, Gee (2000) identificou as perspectivas de identidade - Identidade - N, a Identidade - I, a Identidade $-D$ e a Identidade $-A$ - em sua análise, ilustrando como elas funcionam como ferramenta analítica para pesquisas em Educação. Gee (2000) mostra como a diversidade cultural existente entre os alunos e a maneira como o professor conduz a sua prática profissional, associadas à relação estabelecida entre professor e alunos, são representativas de sua teorização sobre identidade.

Em síntese, Gee (2000) parte de um modelo teórico sobre identidade baseado nas quatro perspectivas abordadas acima. Por um lado, o autor ressalta que essas quatro perspectivas estão inter-relacionadas e, portanto, não podem ser concebidas de forma isolada. $\mathrm{Na}$ interpretação desse teórico, características relativas à natureza do indivíduo não podem ser desprezadas, já que tratam de elementos constituintes de sua identidade. Por outro lado, traços de sua identidade podem ser construídos a partir do papel ocupado na sociedade e da forma como é reconhecido por outras pessoas sem, portanto, deixar de lado as características que são próprias de sua natureza. Ainda, não se pode esquecer o importante papel do discurso na construção da identidade. Por fim, o fato de pertencer a determinados grupos sociais, pela afinidade, também são atributos identitários.

Consideramos como aspecto primordial na construção da identidade as demandas sociais que fazem parte dos diversos contextos dos quais os professores de Matemática participam e como tais demandas estruturam suas identidades. A partir do estudo de Gee (2000), acreditamos ser possível produzir relações entre a construção da identidade da professora Nair e a sua permanência na atividade docente. A permanência na docência pode levar em conta associações entre as Identidade $-N$, Identidade $-I$, Identidade $-D$ e Identidade - A, ou mesmo, a preponderância de uma (ou mais) delas. A escolha pela prática docente até o exercício profissional carrega elementos variados que vão continuamente participando da construção da identidade do professor de Matemática. Ele não pode ignorar a sua natureza; desconsiderar os aspectos biológicos que fazem parte de sua identidade, como também não é possível desconsiderar a sua posição institucional. O professor de Matemática 
não constrói a sua identidade sem levar em conta seu Discurso ${ }^{4}$ e o Discurso dos outros. Ele pode ser reconhecido como um bom professor, exigente ou maluco entre tantos outros estigmas sociais atribuídos ao professor de Matemática, e tudo isso constitui elementos que influenciam sua identidade profissional. A particularidade de sua profissão pode levá-lo ao pertencimento de grupos de afinidade em que interesses comuns vivenciados em sua prática (de sala de aula ou outras) são compartilhados.

\section{Percurso metodológico orientador da pesquisa}

Tendo em vista que este artigo retrata a compreensão dos significados associados às escolhas de Nair pela sua permanência na docência sob a luz de uma perspectiva da identidade, a pesquisa configurou-se como sendo primordialmente qualitativa. De acordo com Groulx (2008), a perspectiva qualitativa contribui para construir análises que se aproximam dos contextos das situações investigadas. Além disso, tal modalidade de pesquisa permite produzir uma descrição da realidade social da professora Nair, buscando entender a forma pela qual ela se percebe, elabora e reflete a sua identidade.

$\mathrm{Na}$ ocasião da pesquisa, Nair atuava no magistério em uma escola da Rede pública estadual de Belo Horizonte e foi convidada a fazer parte da presente investigação. A escolha da Rede pública estadual deveu-se ao fato de que as condições de trabalho nessa Rede eram insatisfatórias, por exemplo, em relação às discrepâncias salariais, se comparadas à Rede pública municipal de ensino.

Como recurso de produção dos dados, empregamos a entrevista de tipo qualitativo semiestruturada, por entender que, por meio da entrevista, poderia, não só capturar as descrições de Nair de si mesmo e de sua realidade, como também indicações de representações de outros sobre ela e de suas interações nas práticas profissionais. O recurso às entrevistas constitui um dos melhores instrumentos capazes de captar o sentido que atores sociais dão as suas ações, num certo momento de suas vidas, considerando que os comportamentos por si sós não conferem a mesma representatividade do discurso dos entrevistados ao falar sobre si mesmos (POUPART, 2008).

As principais perguntas que dirigiram a entrevista com Nair foram: qual(is) o(s) motivo(s) que a fez (fizeram) escolher o curso de Licenciatura em Matemática? Em relação à

\footnotetext{
${ }^{4}$ Gee (2000) estabelece uma distinção entre discurso (letra minúscula $d$ ) e Discursos (letra maiúscula $D$ ). Para ele, o discurso é uma representação do diálogo, via linguagem oral ou escrita. Os Discursos, além de compreenderem a linguagem, se configuram nos modos de ser um determinado tipo de pessoa.
} 
prática docente, qual(is) a(s) principal(is) dificuldade(s) que você enfrenta no exercício de sua profissão? Você já teve a necessidade de afastamento da atividade docente durante a sua trajetória profissional? Em caso afirmativo, explique o(s) motivo(s) para tal afastamento. $\mathrm{O}$ que a mantém na atividade docente? Pretende continuar trabalhando como professora de Matemática? Ao discorrer sobre as perguntas acima, Nair desenhou no tempo diversas etapas de envolvimento com a docência, mencionando aspectos relacionados à escolha da profissão, passando pela formação e a prática docente.

Optou-se por tratar as informações obtidas nas entrevistas como narrativas, partindo-se do princípio de que

[...] a principal razão para o uso da narrativa na investigação educativa é que os seres humanos são organismos contadores de histórias, organismos que individualmente e socialmente, vivem vidas relatadas. O estudo da narrativa, portanto, é o estudo da forma como os seres humanos experimentam o mundo (CONNELLY; CLANDININ, 1995, p. 11).

Nos relatos de Nair, emergiram lembranças, suas histórias recentes e suas perspectivas. Ela ficou livre para dialogar e, dessa forma, a entrevista proporcionou o resgate da memória, contando partes de suas histórias de vida que foram reveladoras da trajetória de sua escolha profissional. "A memória tem a forma de uma narração desde um ponto passado até o presente em função de um ponto de vista que se faz significativo" (LARROSA, 2004, p. 16). Passado e presente apareceram interligados com projeções futuras, sinalizando os caminhos que levaram à permanência na docência.

Ao narrar os acontecimentos que permearam sua vida em torno da escolha profissional, Nair conferia sentido para tais acontecimentos, reorganizando-os em suas experiências nas interações sociais. "Cada pessoa se encontra já imersa em estruturas narrativas que lhe preexistem e em função das quais constrói e organiza de um modo particular sua experiência, impõe-lhe um significado" (LARROSA, 1994, p. 66).

Ao falar de experiência é importante esclarecer o seu significado. A experiência, para Larrosa (2002, p.21), é aquilo que faz sentido para nós: “a experiência é o que nos passa, o que nos acontece, o que nos toca". Essa forma de conceituar a experiência permite ver a narrativa de Nair como uma indicação do sentido atribuído para a escolha profissional. "E a experiência de si está constituída, em grande parte, a partir das narrações. O que somos ou, melhor ainda, o sentido de quem somos, depende das histórias que contamos e das que contamos a nós mesmos" (LARROSA, 1994, p. 47).

Nesta pesquisa, a narrativa apareceu de duas formas. A primeira referiu-se à narrativa de Nair, que emergiu a partir da entrevista de tipo qualitativo semiestruturada; a segunda, diz 
respeito à interpretação e apresentação dos dados de pesquisa na forma de narrativa construída pelo pesquisador, assim como fez Lerman (2012). Para a construção da segunda narrativa, utilizamos a perspectiva de Gee (2000) por entendermos que, dentre as perspectivas de identidade consultadas, ela se mostrava com maior potencial explicativo para interpretarmos e apresentarmos os dados que vinculam o conceito de identidade a desempenhos de indivíduos em contextos sociais. E como os contextos sociais de vida não são, necessariamente, disjuntos, conforme discussão detalhada na seção anterior, não vemos os tipos de identidade propostos por Gee como sendo categorias, excludentes umas das outras.

Para Bruner (1987, p.12), “[...] parece-nos não existir nenhum outro caminho para descrever o tempo vivido, salvo sob a forma de uma narrativa. [...] A narrativa imita a vida, a vida imita a narrativa". Assim, entendemos a narrativa como um construto que privilegia o sentido da experiência. Apoiando-nos nisso, construímos narrativas das narrativas provenientes de Nair, considerando os extratos de sua narrativa como fios condutores para a história contada. Trata-se de uma forma de registrar parte das ações/vivências de Nair como construtora de significados que justificam sua escolha profissional.

Com base no aporte teórico desta pesquisa, acreditamos que o discurso de Nair em sua forma narrativa reflete um conjunto de experiências vividas ao longo do desenvolvimento de suas identidades, podendo sinalizar as suas escolhas profissionais e o sentido construído para a atividade docente. Sob esse ponto de vista, ao narrar suas experiências, Nair traz à tona múltiplas identidades. A esse respeito, Larrosa (2004) argumenta:

\footnotetext{
Minha identidade, quem sou, não é algo que progressivamente encontro ou descubro ou aprendo a descobrir melhor, e sim algo que fabrico, que invento e que construo no interior dos recursos semióticos de que disponho, do dicionário e das formas de composição que obtenho das histórias que ouço e que leio, da gramática; em suma, que aprendo e modifico nessa gigantesca e polifônica conversação de narrativas que é a vida (LARROSA, 2004, p. 20).
}

Em nossas narrativas apresentamos quem somos, nossas crenças e desejos. Situamos nossas ações para nós mesmos e para os outros por meio de nossas experiências e, dessa forma, vamos construindo e reconstruindo identidades no tempo (LARROSA, 1994; FREITAS; FIORENTINI, 2007). Cabe dizer que, assim como as identidades, as narrativas são continuamente reconstruídas de acordo com as experiências que os indivíduos vivenciam.

As ideias de Gee (2000) acerca do construto identidade foram aquelas que apoiaram a interpretação dos dados. Na narrativa que construímos, interpretamos as experiências narradas na entrevista, ou seja, a narrativa de Nair, buscando indicações dos tipos/perspectivas de identidade elencados por Gee (2000) e procurando relacioná-las ao fenômeno da permanência na prática docente. Trata-se, portanto, de um exercício essencialmente interpretativo. 
Sinalizamos os tipos/perspectivas predominantes de identidades elencados por Gee (2000): Identidade Institucional e Identidade Discursiva (os tipos Identidade de Afinidade e Identidade Natural não foram identificados nas entrevistas). Como nesta pesquisa não observamos Nair em interações em sua prática profissional, tomamos, como evidência de manifestação da Identidade Discursiva, suas indicações de como acreditava ser ou gostaria de ser reconhecida na profissão e/ou em seus ambientes de trabalho, ou de como conduzia ou gostaria de conduzir a sua prática.

\section{Nair - vocação pela docência - a força da identidade institucional}

Nair era professora de Matemática no Ensino Fundamental, em uma instituição localizada na região central de Belo Horizonte, e sem problemas relacionados à rotatividade de professores e à violência no contexto escolar. Fundada há 83 anos, essa instituição apresentava boas referências sociais. Tratava-se de uma escola que já foi considerada uma das melhores da cidade. Mesmo assim, a instituição não estava isenta de problemas no contexto escolar, como veremos mais adiante.

Além de atuar como professora na Rede pública estadual, Nair lecionava em uma unidade escolar da Rede municipal de ensino na Região Metropolitana de Belo Horizonte para o Ensino Fundamental. Ela era efetiva em ambos os cargos. Na época da pesquisa, Nair estava com 50 anos de idade e, já prestes a se aposentar, totalizando 26 anos de experiência no magistério. Ela dedicava 40 horas semanais à atividade docente. A docência não foi a primeira escolha profissional de Nair. O seu desejo era fazer o curso de Engenharia Química, mas precisava trabalhar e não podia se dedicar aos estudos em horário integral, conforme demanda do curso pretendido. Sendo assim, Nair decidiu fazer o curso de Licenciatura em Matemática, pois se tratava de um curso noturno e não lhe impediria de trabalhar. Além disso, a docência também lhe atraia profissionalmente.

Sua decisão em construir uma identidade institucional de professora de Matemática se deu por dois motivos: (i) sempre gostou da disciplina; (ii) teve um professor de Matemática que a influenciou, positivamente, a seguir na carreira docente. Além do gosto pela Matemática, Nair declarou, também, seu desejo pelo magistério (desejo de assumir uma identidade institucional: professora de Matemática por vocação), fato que se associou à sua experiência como aluna de um professor de Matemática que marcou positivamente a sua trajetória escolar. "Eu sempre gostei de Matemática, mas o que me fez escolher Matemática 
foi um professor que eu tive. Eu fiz Matemática por causa dele. Eu gostava de Matemática. Eu sempre quis ser professora. Tanto é que eu fiz magistério".

Durante a entrevista, Nair demonstrou entusiasmo e satisfação ao falar sobre a influência desse professor na sua escolha profissional, mostrando ter construído, naquela ocasião, uma imagem positiva sobre o que é ser professor. Em relação à opção pela atividade docente, Tartuce, Nunes e Almeida (2010, p. 475) argumentam que “[...] não se pode desconsiderar a imagem que os próprios professores constroem de si próprios - em palavras ou em atos - e que acaba influenciando seus alunos. Essa influência, quando positiva, pode se refletir em fatores de atração da carreira docente".

Diante do exposto, tem-se que a manifestação da identidade institucional predominou no relato de Nair acerca de sua escolha pelo curso de Licenciatura em Matemática. Isso quer dizer que a busca por uma posição social sustentada institucionalmente foi o principal fator que a influenciou na escolha profissional. Constatou-se, com firmeza, o desejo de Nair em construir uma identidade institucional como professora por vocação.

O curso de licenciatura foi relevante para a formação profissional de Nair e para a prática em sala de aula. Para ela, a formação para a docência teve o significado de um instrumento para o desenvolvimento do seu trabalho. Nair sugeriu que as disciplinas de didática foram fundamentais para a sua formação. "A didática, na minha época, foi muito boa. Aprendi muita coisa com o Renato e com a Elza, que foram meus professores. Então, eu já tinha uma boa base e só tive que me aperfeiçoar".

De maneira geral, ela apresentou somente aspectos positivos em relação à sua formação profissional. A esse respeito, Brown e Macnamara (2011) destacam que a formação do professor e a construção da identidade profissional estão completamente imbricadas. Nair investiu, também, em dois cursos de Pós-graduação lato sensu: uma especialização em Matemática e, outra, em Didática de Ensino.

Para Nair, o curso de licenciatura não deveria ser o único responsável pela construção de saberes da prática do professor em sala de aula. De acordo com ela, cabe ao professor a busca contínua de novos saberes que poderão auxiliá-lo no trabalho. Além disso, em sua concepção, a sala de aula representa um espaço de formação profissional, já que a profissão requer uma preparação constante, visando levar o estudante a se interessar pela Matemática.

O conhecimento eu acho que a gente busca ele a todo o momento. Porque, por exemplo, eu faço curso direto (busca por redescrições de sua identidade discursiva). Então, mesmo para aperfeiçoar em questão de didática. Então, eu ainda vou buscando. Você vai descobrindo, cada vez mais você vai descobrindo uma técnica melhor para ensinar. Eu levo os meninos a gostar de Matemática mesmo (NAIR, 2010). 
Desde a sua escolha profissional, passando pela formação até o momento em que ingressou na docência, Nair tecia um jeito de ser como professora que era constantemente reelaborado. Ao longo dessa trajetória, ela incorporava valores e atitudes que concebia como essenciais para o exercício da profissão. Tais valores e atitudes, declarou Gómez-Chácon (2010), participam da construção de sentido para a profissão e, consequentemente, da construção do que a autora chama de identidade profissional.

Nair caracterizou a busca por desenvolvimento profissional como aperfeiçoamento para a docência. Krzwacki e Hannula (2010) observaram que tal busca é resultante das disparidades entre a identidade no presente e a identidade ideal/almejada. Na ocasião da pesquisa, vimos o relato de Nair como manifestação de suas identidades institucional e discursiva no presente. Seu desejo incessante de investir em novos saberes para a prática revelou a projeção daquilo que ela buscava para os alunos: o despertar de um gosto pela Matemática. Nair sempre esteve em busca de algo novo para auxiliá-la na prática pedagógica; não se contentava com a sua identidade discursiva a cada presente; estava sempre a redescrever sua identidade discursiva almejando o ideal.

A prática de Nair não era nenhum paraíso. O depoimento a seguir mostra as dificuldades que ela encontrava no trabalho: "o que eu acho que me atrapalha mais é quando o aluno não faz as atividades e aluno sem interesse. A dificuldade que eu tenho é essa questão do pai não estar ajudando em casa, da família mesmo". Essas dificuldades, contudo, não eram entraves para a permanência de Nair na docência. Em relação aos alunos, ela disse: "eu tenho que conquistar o aluno e fazer com que ele aprenda a sua atividade. Conquisto esse menino para levar que ele goste de Matemática”. Além disso, manifestou aspectos de sua identidade discursiva (reconhecimento de si) dizendo:

\footnotetext{
Eu sou dedicada, eu sou esforçada. Então, assim, eu não gosto de chegar atrasada. Eu sou muito dedicada, tudo que eu faço eu gosto de fazer bem feito. Eu levo o meu aluno a gostar de Matemática, procuro facilitar ao máximo, para que ele aprenda e não pense que Matemática é um bicho de sete cabeças. Tanto é que desde a primeira Olimpíada de Matemática eu tive um medalhista (NAIR, 2010).
}

Nair também relatou que os alunos reconheciam seu trabalho de forma positiva. A trajetória de Nair na construção de sua identidade discursiva como professora de Matemática sofria influência da imagem que tinha de si mesma como profissional, do que ela se sentia em relação aos alunos e da forma como acreditava ser reconhecida pelo seu trabalho: "eu estive aqui sábado de manhã. Você precisava ver o alvoroço de alunos do $2^{\circ}$ grau que vêm para me ver. Para me ver, para falar para mim se eu vou dar aulas para eles no ano que vem. E eu estou me aposentando". 
O valor que Nair atribuía à docência direcionava a sua prática pedagógica. E a questão salarial não era, para ela, motivo de desmotivação no trabalho: "então, o pessoal fica falando de salário... Quando eu entro esqueço quanto eu ganho. Eu trabalho, porque eu gosto. Eu acho que o magistério, hoje, se você não gostar você não fica, ou não faz um bom trabalho". À frente de qualquer problema estava a sua satisfação em lecionar, reforçando sua forte identidade institucional.

O prazer em relação ao trabalho pareceu ser o principal fator de motivação para a permanência de Nair no magistério. Ao ser questionada sobre o que a mantinha na docência, Nair reforçou sua identidade institucional de professora por vocação, dizendo: "Eu dou aula porque eu gosto. É um vício! Eu gosto de dar aula. Eu gosto de ensinar. Tanto que eu estou me aposentando, mas não vou abandonar o magistério. Vou continuar, porque eu gosto de dar aula. Eu gosto de ensinar!"

A imagem que Nair criou de si mesma como professora é produto do que ela entendia sobre o processo de ensino e aprendizagem.

Sintetizando, acerca da permanência na docência, produziram-se evidências da força de uma identidade institucional como principal fator que mantinha Nair na profissão. Cabe ressaltar que é preciso estabelecer uma vigilância teórica ao realizar o mapeamento das identidades de Nair. O prazer que a professora menciona com o trabalho e a boa relação que construiu com os alunos não se tratam de manifestações da identidade de afinidade na perspectiva teórica de Gee (2000), mas de um caráter afetivo. A Identidade de Afinidade é identificada a partir das experiências vivenciadas em grupos de afinidade - o que não foi manifestado na narrativa de Nair.

Nair manifestou a força de sua identidade institucional permanecendo na docência. Tal força foi evidenciada pelo prazer que a prática docente lhe proporcionava. Em outras palavras, tal tipo de identidade mostrou ser o principal motivo de permanecer na docência, sustentada por vocação, conforme discutido por Gee (2000).

\section{Considerações finais}

A narrativa da permanência de Nair na atividade docente converge para a abordagem de Gee (2000) sobre a construção identitária, em termos dos seguintes aspectos: (i) identidades são dinâmicas e estão em desenvolvimento contínuo; (ii) identidades são construídas nos diversos contextos de que os sujeitos participam; (iii) a construção de identidades pressupõe o reconhecimento de outros (indivíduos, instituições). Ainda, como 
sugerido por Frade e Meira (2010), tivemos indicações de que identidades não se constroem em função apenas dos desejos e julgamentos pessoais dos sujeitos, mas, talvez e, sobretudo, em função das contingências e circunstâncias a que esses sujeitos estão submetidos em certo momento de suas vidas.

Nair optou pela prática docente para construir uma identidade institucional por vocação e manifestou esta identidade como forte influência para permanecer na prática docente. Ela reforçou sua identidade institucional ao relatar o seu prazer com a atividade docente. Ao interpretar o fenômeno da permanência nessa profissão na perspectiva de Gee (2000), vimos como as identidades de Nair se manifestavam em relação a dois subcontextos particulares do trabalho docente: o institucional, ditado pelas forças da instituição à qual pertencia, e o discursivo, referente a como ela se reconhecia e/ou acreditava ser reconhecida em seu ambiente de trabalho, bem como interagia com os alunos em sua prática. Tal perspectiva possibilitou uma interpretação dos dados em função, não somente dos desejos, escolhas e julgamentos pessoais, mas também das contingências e circunstâncias a que Nair estava sujeita em certos momentos de sua vida (FRADE; MEIRA, 2010). A combinação dessas circunstâncias e escolhas pessoais sugere que existe uma constante negociação entre as identidades dos professores de Matemática e os contextos de trabalho de que participam, dos quais a prática de sala de aula é um deles.

A partir dessa pesquisa, indicamos que a identidade docente é sempre reconstruída num contexto histórico e social que transforma constantemente as ações do professor no seu ambiente de trabalho e na sua prática profissional. Ao construir uma identidade discursiva que permita uma representação positiva da profissão, o professor de Matemática pode reforçar sua identidade institucional, porque o sentido conferido à profissão está relacionado à maneira pela qual o professor é reconhecido profissionalmente pela sociedade.

\section{Referências}

BOALER, J. The development of disciplinary relationships: knowledge, practice and identity in mathematics classrooms. For the Learning of Mathematics, Stanford, v. 22, n. 1, p. 42-47, 2002.

BOALER, J.; WILLIAM, D.; Zevenbergen, R. The construction of identity in secondary mathematics education. In: MATOS, J. F.; SANTOS, M. (Ed.). Proceedings of the 2nd International MES Conference. Lisboa: Centro de Investigação em Educação da FCUL, 2000. p. 192-202.

BRASIL. Estatísticas dos professores no Brasil. Ministério da Educação/INEP, 2003. Disponível em: 〈http://www.inep.gov.br/estatisticas/professor2003 >. Acesso em: 12 abr. 2010. 
BRASIL. Escassez de professores no Ensino Médio: propostas estruturais e emergenciais. CNE/ CEB, 2007. Disponível em: 〈http://portal.mec.gov.br/cne/arquivos/pdf/escassez1.pdf>. Acesso em: 12 abr. 2010.

BROWN, T. Mathematical identity in initial teacher training. In: DOUGHERTY, B .J; ZILLIOX, J. (Ed.). Proceedings of the 2003 Annual Meeting of the International Group for the Psychology of Mathematics Education. Honolulu: PME, 2003. v. 2. p. 151-156.

BROWN, T., MCNAMARA, O. Becoming a Mathematics Teacher: identity and Identifications. London: Springer, 2011.

BRUNER, J. Life as narrative. Social Research, New York, v. 54, n. 1, p. 11-32, 1987.

CONNELLY, M.; CLANDININ, J. Relatos de Experiencia e Investigacion Narrativa. In: LARROSA, J. Déjame que te cuente: ensayos sobre narrativa y educación. Barcelona: Laertes, 1995, p.11-59.

FIORENTINI, D. A Pesquisa e as práticas de formação de professores de matemática em face das políticas públicas no Brasil. Bolema - Boletim de Educação Matemática, Rio Claro, v. 21, n. 29, p. 43 70, 2008.

FRADE, C.; MEIRA, L. The Social Nature of Affective Behaviors and the Constitution of Identity. In: PINTO, M; KAWASAKI, T. (Ed.). Proceedings of the 34th Conference of the International Group for the Psychology of Mathematics Education. Belo Horizonte: PME, 2010. v. 1. p. 262-266.

FREITAS, M. T. M; FIORENTINI, D. As possibilidade formativas e investigativas da narrativa em educação matemática. Revista Horizontes, Itatiba, v. 25, n. 1, p. 63-71, jan./jun. 2007.

GAMA, R. P.; FIORENTINI, D. Identidade de professores iniciantes de matemática que participam de grupos colaborativos. Revista Horizontes, Itatiba, v. 26, n. 2, p. 31- 43, jul./dez. 2008.

GÓMEZ-CHACÓN, I. M. The local and the global affective structures in mathematics learning and the construction of professional identity. In: PINTO, M; KAWASAKI, T. (Ed.). Proceedings of the 34th Conference of the International Group for the Psychology of Mathematics Education. Belo Horizonte: PME, 2010. v. 1. p. 272-277.

GEE, J. P. Identity as an Analytic Lens for Research in Education. Review of Research in Education, Madison, v. 25, p. 99-125, 2000.

GOLDIN, G.; ROESKEN, B.; TOERNER, G. Professionalism and identity - on the structured NATURE of affect, motivation, and beliefs. In: PINTO, M; KAWASAKI, T. (Ed.). Proceedings of the 34th Conference of the International Group for the Psychology of Mathematics Education. Belo Horizonte: PME, 2010. v. 1. p. 250-256.

GROOTENBOER, P.; SMITH, T.; LOWRIE, T. Researching identity in mathematics education: the lay of the land. In: GROOTENBOER, P; ZEVENBERGEN, R.; CHINNAPPAN, M. (Ed.). Proceedings of the 29th Annual Conference of the Mathematics Education Research Group of Australasia. Adelaide: PME, 2006. v. 2. p. 612-615.

GROULX, L. H. Contribuição da pesquisa qualitativa à pesquisa social. In: POUPART, J. et al. (Org.). A Pesquisa Qualitativa: enfoques epistemológicos e metodológicos. Petrópolis: Vozes, 2008. p. 95-124.

HODGEN, J. Identity, motivation and teacher change in primary mathematics: a desire to be a mathematics teacher. In: MCNAMARA, O. (Ed.). Proceedings of the British Society for Research into Learning Mathematics. London: BSRLM, 2004, v. 24, n. 1. p. 31-36. 
KRZYWACKI, H. \& HANNULA, M. Tension between present and ideal state of teacher identity in the core of professional development. In: PINTO, M; KAWASAKI, T. (Ed.). Proceedings of the 34th Conference of the International Group for the Psychology of Mathematics Education. Belo Horizonte: PME, 2010. v. 1. p. 267-271.

LARROSA, J. Notas sobre narrativa e identidade. In: ABRAHÃO, M. H. M. B. (Org.). A aventura (Auto) Biográfica: teoria e empiria. Porto Alegre: EDIPUCRS, 2004.

LARROSA, J. Tecnologias do eu e educação. In: SILVA, T. (Org.). O sujeito da educação. Petrópolis: Vozes, 1994. p. 35-86.

LARROSA, J. Notas sobre a experiência e o saber de experiência. Revista Brasileira de Educação, Rio de Janeiro, n. 19, p. 20-28, jan./fev./mar./abr. 2002.

LERMAN, S. Learning mathematics as developing identity in the classroom. In: LILJEDHAL, P. (Ed.). Proceedings of the Canadian Mathematics Education Study Group. University of Ottawa: CMESG, 2006. p. 3-13.

LERMAN, S. Agency and identity: Mathematics teachers stories of overcoming disadvantage. In: Tso, T. Y. (Ed.). Proceedings of the $36^{\text {th }}$ International Conference of the International Group for the Psychology of Mathematics Education. Taipei: PME: 2012. v. 3. p. 99-106.

OCDE. Professores são importantes: atraindo, desenvolvendo e retendo professores eficazes. São Paulo: Moderna, 2006.

OCDE. Guide TALIS 2013 à l'intention des enseignants: enquête internationale sur l'enseignement et l'apprentissage. Talis: Éditions OCDE, 2014.

ODELIUS, C. C.; RAMOS, F. Remuneração, renda, poder de compra e sofrimento psíquico do educador. In: CODO, W. (Org.). Educação: carinho e trabalho. Rio de Janeiro: Vozes, 1999. p. 338354.

PAZ, M. L. da. A permanência e o abandono da profissão docente entre professores de Matemática. 2013. 165 f. Tese (Doutorado em Educação) - Universidade Federal de Minas Gerais, Belo Horizonte, 2013.

PONTE, J. P. Perspectivas de desenvolvimento profissional de professores de Matemática. In: PONTE, J. P.; MONTEIRO, C.; MAIA, M.; SERRAZINA, L.; LOUREIRO, C. (Ed.).

Desenvolvimento profissional de professores de Matemática: que formação? Lisboa: SEM-SPCE, 1995. p. 193-211.

PONTE, J. P.; OLIVEIRA, H.. Remar contra a maré: a construção do conhecimento e da identidade profissional na formação inicial. Revista de Educação, Lisboa, v. 11, n. 2, p. 145-163, 2002.

POUPART, J. A entrevista de tipo qualitativo: considerações epistemológicas, teóricas e metodológicas. In: POUPART, J. et al. A Pesquisa Qualitativa: enfoques epistemológicos e metodológicos. Petrópolis: Vozes, 2008. p. 215-253.

SFARD, A.; PRUSAK, A. Telling identities: in search of an analytic tool for investigating learning as a culturally shaped activity. Educational Researcher, Washington, v. 34, n. 4, p. 14-22, 2005.

TARTUCE, G. L. B. P.; NUNES, M. M. R.; ALMEIDA, P. C. A. Alunos do ensino médio e atratividade da carreira docente no Brasil. Cadernos de Pesquisa, São Paulo, v. 40, n. 140, p. 445477, mai./ago. 2010. 
WALSHAW, M. Preservice mathematics teaching in the context of schools: an exploration into the constitution of identity. Journal of Mathematics Teacher Education, New York, v. 7, n. 1, p. 63-86, 2004.

Submetido em Junho de 2015. Aprovado em Outubro de 2015. 